\title{
O DESEJO E A REPRESENTAÇÃO NAS GRAVURAS ERÓTICAS JAPONESAS SHUNGA
}

Amaury A. Garcia Rodriguez ${ }^{2}$

RESUMO: Quais são as relações que se constituem entre o desejo e o consumo nas representações visuais? É possível descobrir estruturas projetadas expressamente para desencadear desejos particulares? Tomando algumas dessas inquietações como ponto de partida, este artigo tem a intenção de aprofundar as relações entre desejo e sua representação nas gravuras eróticas japonesas shunga.

PALAVRAS-CHAVE: Shunga, gravuras japonesas, arte erótica, cultura popular.

ABSTRACT: Which are the kind of relations that emerge linking desire and consumption within visual representations? It is possible to reveal certain structures just projected to generate particular desires? Departing from some of these questions, this article examines the interaction between desire and its representation at the Japanese erotic prints production (shunga).

KEYWORDS: Shunga, Japanese prints, erotic art, popular culture.

Essenciais no que hoje é isso que chamamos shunga ou makura-e são os diferentes processos de sua conversão em bem de consumo e de singularização que ocorreram desde

1. Eu agradeço sinceramente a Hayakawa Monta e a Madalena Hashimoto para o cordial convite a participar da sessão sobre as gravuras eróticas japonesas, que foi levada a cabo como parte do simpósio. Este texto não tinha sido possível sem a revisão amável, por parte de Madalena, de meu precário manuscrito em português. A ela transmito minhas considerações por aquele esforço, como também para as suas atenções em São Paulo. Minhas gratidões para Hosokawa Shuhei, Kita Yoshifumi, Junko Ota e os outros colegas de CEJAP e Nichibunken para esta possibilidade.

2. Centro de Estudios de Asia y África -El Colegio de México: amaury@colmex.mx 
o período Edo (1603-1868) até os nossos dias. Neles, mais que de uma identidade única, deveríamos falar de uma mutação constante (e, portanto, em uma multiplicidade de sentidos que as acompanham), dependente de sua biografia, de suas mudanças de status e de circuitos de circulação e consumo, e de imposições categoriais, entre muitos outros fatores. Apesar da época em que foram produzidas, o período Edo, várias das faces complexas destas imagens se originaram em estimações e discursos recentes que tentam apresentar como sendo geral setores de cenários parciais da história do shunga, o que, também, contribuiu para gerar fortes polêmicas.

Claro que muitos destes discursos resultam de práticas que nomeamos como "modalidades de apropriação", seguindo as palavras de Roger Chartier, que também esclarece: As obras, realmente, não têm um sentido estável, universal, ou fixo. Elas são investidas de significações plurais e móveis, construídas quando do reencontro entre uma proposição e uma recepção entre as formas e os motivos que lhes dão sua estrutura, e as competências $e$ as expectativas dos públicos que se apropriam delas. ${ }^{33}$ No caso do shunga, esta produção de significados e, principalmente, de usos é também marcada pelo suposto papel de que estas imagens seriam estimulantes sexuais.

Como parte da mitologia do shunga, as histórias, anedotas e discussões de suas possiveis funções e usos ocupam um lugar destacado em praticamente cada um dos textos recentes que se dedicam a seu estudo. Além de ser proclamado que uma das suas aplicações mais antigas tenha sido a educativa, e que além disso teria sua origem em terras continentais, com ofangzhong-shu chinês, freqüentemente são também mencionados outros usos legendários: resguardo para os guerreiros (escondido nas armaduras), proteção contra fogo, tremores e desastres, e atração de sorte, entre outros. Estas propriedades "milagrosas" que fontes antigas conferem ao shunga, e outras não tão distantes no tempo, têm algo em comum: todas têm laços muito longínquos com as situações geralmente representadas nestas imagens, centradas em sexo.

Independentemente dos ânimos absolutistas e restritivos com respeito aos usos do shunga, se revisarmos algumas fontes do período Edo, notaremos que as situações são mais variadas do que se pretende apresentar em certas ocasiões:

(...) Por outro lado, há imagens de sexo entre homens e mulheres que se chamam shunga $e$ warai-e, entre outros nomes. Há muitos tipos de livros impressos; todos os anos são encomendados títulos novos com cores muito vivas, até mesmo com impressões douradas e prateadas. Diz-se que eles ficam na parte da entrada das

3. Chartier, Roger. El mundo como representación. Estudios sobre historia cultural. Gedisa, Barcelona, 1995, p:XI. 
lojas de comerciantes. Além disso, a exibição destas imagens parece não irritar a pais e irmãos, que as vêm como diversão. As mulheres e meninas que as colecionam dizem que elas são amuletos para lhes propiciar mais roupas e as guardam na mobilia e nos baús das vestes, e, inclusive, há mães que dão tais imagens como herança às filhas (Fragmento do livro Seji kenbun-roku, de Buyō Inshi, 1816). ${ }^{+}$

(...) O conteúdo desta arca pertence à senhora de nosso daimio. Trata-se de ferramentas de mão feitas sob encomenda e abastecimentos de livros eróticos. Mesmo que esteja registrado o nome dela nesses utensílios sexuais (...) (Fragmento do livreto de teatro kabuki Kanadehon Chusshingura, de Takeda Izumo, Miyoshi Shōraku e Namiki Senryū, 1748)..$^{55}$

Claro que seria completamente irracional tentar desvestir o shunga de suas evidentes implicações sexuais. As evidências são muito contundentes (a partir das referências escritas e da própria manifestação) para não se levar em conta o decisivo papel do shunga como estimulante sexual. Contudo, apesar de haver opiniões contrárias a esses usos legendários, que dizem ser muito provável que alguns deles tenham surgido como recreações líricas, ou que têm justificações tangenciais e alienadas do seu consumo (que talvez com o tempo e a repetição teriam se afirmado, fixado e gerado usos reais), e que consideram que certamente tais não foram das funções mais difundidas, eu considero que eles são fatores importantes para se levar em conta, já que é impossível se restringir a complexidade de usos que pode ter um objeto ou uma imagem somente aos que os criadores pretenderam, ou aos que nós achamos mais pertinentes, ou aos que nos parecem mais evidentes.

Afastando-nos das polêmicas geradas quanto às funções do shunga, com as quais concordo apenas parcialmente, e levando em consideração a impossibilidade de generalizar esses usos a posteriori (ou mesmo a priori), podemos afirmar que alguns deles eram mais extensivos que outros. Neste sentido, e partindo do tópico desta sessão "Expressões do Erotismo Japonês" nos interessaria aqui analisar as relações entre a representação e a gratificação sexual. Esta estimulação poderia ser efetuada em dois campos básicos que dependeriam das necessidades e dos desejos do consumidor: no plano da fantasia e no do ato físico (fosse este na forma de auto-erotismo ou de combinação com um casal ou grupo). Destes dois, considero que o campo mais dinâmico, interessante e possivelmente mais de-

4. Buyō Inshi 武陽媱士. Seji kenbun-roku世事見聞録 (1816). Iwanami Bunko, Tóquio, 2002, p: 360.

5. Takeda Izumo 竹田出雲, Miyoshi Shoraku 三好松洛 \& Namiki Senryu 並木千柳. Kanadehon Chūshingura 仮名手本忠臣蔵 (1748). University of Virginia Electronic Text Center, Charlottesville, 1999. Disponivel em World Wide Web em http://etext.lib.virginia.edu/japanese/chushingura/TakKana.html (15 de Abril de 2006) 
senvolvido é o terreno das recreações mentais. Nele, como Elizabeth Cowie ${ }^{6}$ aponta, a imagem constrói um cenário de fantasias onde são representados certos desejos, sublimados na mente do espectador. Deste modo, creio que só a partir desta remodelação imaginária dos níveis enaltecedores da sua operação no espectador é que pode se originar alguma resposta fisiológica ou simplesmente ficar na manipulação mental de uma fantasia. Ainda que eu compartilhe com o argumento da necessidade de ponderar esta produção como um estimulante sexual, parece-me que não deveríamos ser exclusivos para com seus usos.

Quer dizer que reduzindo-se as utilidades (e respostas) que puderam e podem gerar os shunga a intelectuais, simbólicas ou físicas, não só se torna parcial um princípio (como é corrente) que ninguém pode predizer, mas também se continua homogeneizando o próprio nome shunga. Teria toda essa amálgama de exemplos que são denominados shunga, realmente se imposto de um mesmo modo? Não seria melhor considerar que cada um dos tipos dentro daquela produção que é generalizada como shunga, previu mercados e, portanto, funções diferentes? Afastando-nos dos usos, seria possível descobrir testemunhos no próprio makura-e de estruturas desenhadas expressamente para desencadear reações particulares? Poderíamos ancorar parte das causas desses usos mais difundidos (em particular o estímulo sexual) somente no criador, ou também no consumidor, ou, ainda no objeto em si? Se assim fosse, quais seriam os mecanismos e as estratégias?

Revisemos, então, algumas observações ao redor da relação entre o desejo, a imagem, e o shunga.

Partiremos reconhecendo que historicamente a visualidade foi marcada pela prevalência de um olhar masculino. A história das imagens no Japão, claro, não esteve livre destas políticas da visão? representação do sexo, e nas diferentes visões que tradicionalmente foram construídas pelo espectador masculino, e que não só evocaram significações como também diferiram no ato final do consumo, e matizaram de igual forma o processo de elaboração da imagem.

Se nós também levamos em consideração a importância da imagem ${ }^{8}$ nos processos de configuração disso que chamamos "realidade" ou "mundo", e da própria consistência da memória e da evocação de experiências, a necessidade do ato de olhar adquire uma relevância contundente em nossa própria condição humana. Somos seres ávidos de "olhar." Este ato, que é talvez um dos

6. Cowie, Elizabeth. "Pornography and fantasy. Psychoanalytic perspectives", em Segal, Lynne, ed. Sex exposed. Sexuality and the pornography debate. Virago Press, Londres, 1992, pp. 132-152.

7. Ueno Chizuko o chama, "supremacia da mirada" (shisen no yui 視線の優位). Ueno Chizuko 上野千鶴子 “Shisen no sei = seijigaku" 視線の性=政治学, em Shirafuji Kayako 白藤花夜子, ed.. New feminism review ニューフフェミニ゙ム レビュー Vol. III, Porunogurafi, yureru shisen no seiji-gaku ポルノグラフィ 一、摇れる視線の政治学. Gakuyō Shobō, Tóquio, 1992, pp: 92-100.

8. Estou partindo da definição de imagem de W.J.T. Mitchell. Mitchell, W. J. T. Iconology. Image, text, ideology: The University of Chicago Press, Chicago, 1986. 
mais poderosos desejos, nos ajuda a definir-nos, da mesma maneira que assumimos o que somos. Então, este ato de olhar também trabalhará como rememorativo ao desejo.

${ }^{9}$ Reforçando o papel do desejo neste ato de olhar, é importante ter presente a permanente prontidão da imagem em tal ato. Sempre está lá, pronta para o olho, disposta a revelar todos seus segredos. Daí a importância da posse do objeto, que se soma como um componente a mais nas redes estruturais do olhar, e em particular (como mencionamos antes) do olhar por excelência, o masculino ${ }^{9}$. A imagem foi assumida não só como posse e bem de consumo, mas também como catalítica de desejos que recriam em nível mental (e às vezes físico) experiências inevitavelmente desencadeadoras de reações químicas que afetam ou embriagam o ambiente fisico de nosso corpo.

Agora, que é o que se procura do shunga? Ou, melhor dito, o que foi que se procurava do shunga em Edo? Aqui, novamente, podemos voltar ao círculo interminável das possibilidades infinitas. Consumo? Diversão? O objeto em si? Desejos virtuais de luxo, ou de status? Experimentar um Yoshiwara virtual? Compartilhar mentalmente com alguma prostituta, mulher ou ator de kabuki famoso? Levar a cabo fantasias sexuais? Libertar-se de sua própria cotidianidade? As probabilidades nas respostas, novamente, dependerão da dialética entre uma imagem e um possuidor particulares, das convenções que são usadas para a construção daquele desejo, e dos modos como essas convenções funcionam num contexto particular.

Não obstante, esta "corporificação do desejo sexual"10 no caso do shunga, pode ser rastreada através de uma abundância de recursos que a enfatiza: genitais, objetos, detalhes, cores, ausências, bisbilhoteiros, lentes, espelhos, ângulos, entre outros. ${ }^{1}$ Para uma melhor organização na relação de várias das estratégias de representação e de critérios de seleção mais representativos para esses propósitos de que faz uso o makura-e, apoiar-me-ei na idéia da "visibilidade boa" concebida pelo pesquisador espanhol Román Gubern. ${ }^{12}$

Uma delas é a fragmentação anatômica. Este mecanismo que segmenta essas partes do corpo que se consideram de maior importância pela concentração da atenção erótica (os genitais e as faces), é talvez o mais freqüentemente utilizado no shunga em

9. Mitchell, W.J.T.. "What do pictures 'really' want?", em October. Vol. LXXVII. MIT Press, Cambridge, 1996, pp: 71-82. Outro texto interessante de revisar é: Bryson, Norman, Michael Ann Holly \& Keith Moxey, eds. Visual culture. Images and interpretations. Wesleyan University Press, Hanover, 1994.

10. Fazendo uso da frase de Freedberg (embodiment of sexual desire). Freedberg, David. The power of images: Studies in the history and theory of response. The University of Chicago Press, Chicago, 1989.

11. Screech, Timon. Sex and the floating world. Erotic images in Japan 1700-1820. University of Hawaii Press, Honolulu, 1999; Tanaka Yuko. Erotic textiles, em Jones, Sumie, ed.. Imaging/Reading eros. Proceeding for the conference: Sexuality and Edo culture, 1750-1850. Indiana University, Bloomington, 1996, pp: 63-68; e Tanaka Yako 田中優子 “Shunga no kakusu - misen”” 春画の隠寸 見せる, em Shirakura Yoshihiko 白倉敬彦, ed., Ukiyo-e shunga wo yomu 浮世桧春画を読むs. Vol. I. Chūō Koron-sha, Tóquio, 2000, pp: 87-162.

12. Gubern, Roman. La imagen pornográfica y otras perversiones ópticas. Akal, Barcelona, 2004. 
geral. Quase sempre, ainda, vai acompanhado pelos modos em que se dispõem as roupas dos personagens e outros acessórios (como cortinas, portas corrediças, mosquiteiros ou colchas), que amiúde possuem um nível de detalhe e de cores que contrasta com a brancura dos corpos e acentua a mesma segmentação. Outras vezes esta fragmentação caminha em sentido contrário à exibição clara dos genitais, e tira proveito dos objetos mais diversos em cena para multiplicar os acessos visuais a estas áreas fracionárias, ou, ao contrário, escondeos para estimular a fantasia do receptor que tem que completar deste modo "o que falta"

A imediação do componente sexual será outro ingrediente efetivo nestas convenções que o makura-e incorpora. Isto é possível por três manobras que podemos apreciar nos exemplos seguintes. Em primeiro lugar, os arranjos na composição e disposição das figuras que nos permitem um acesso límpido ao centro do estímulo dominante visual, quer dizer, os genitais. Sua solução nos exemplos se aplica desabrigando a área genital, colocando o ponto de vista em um campo de visibilidade fácil, ou efetuando um grande close-up. O segundo e terceiro ingredientes estão diretamente relacionados com as alterações do corpo humano, ou de partes dele: a desarticulação do corpo e a dimensão exagerada dos genitais (tanto masculinos como femininos). Ambos também são orientados a alcançar uma claridade na focalização do centro de atenção visual, enquanto se rompe completamente com qualquer tipo de consideração sobre a "correção anatômica." Elas são, talvez, duas das características do shunga que continuam chamando a atenção hoje, e sobre as quais os habitantes de Edo tampouco se mostravam alheios, como nos mostra este fragmento do livro Kinsei füzoku-shi, de Kitagawa Morisada, 1863:

Se uma pessoa observa o shunga de hoje, nota que o pênis é surpreendentemente grande e não mantém relação com o ser humano. Além disso, é totalmente desproporcionado. ${ }^{13}$

Com bastante frequência é adjudicado ao espectador, e não à imagem, a carga inteira nestas categorizações. Sendo certo que o peso maior reside nos modos em que um consumidor se apropria do objeto e, portanto, nos modos em que este é visto e classificado na comunidade cultural onde foi inserido, é importante lembrar que o artista também tem a capacidade de induzir respostas e interpretações determinadas a partir da representação mesma, e que a imagem, também, nunca permanece indiferente nem ingênua em suas relações com os receptores.

Esta característica da imagem, e do shunga em particular, de propiciar respostas marcadas pela estimulação sexual que são induzidas por redes de signos, e que podemos

13. Kitagawa Morisada 喜田川守貞. Kinsei fuzoku-shi 近世風俗志 (1863). Vol. II. Iwanami Bunko, Tóquio, 2003, p: 80. 
chamar "efeito desencadeante", é perfeitamente sustentável por conta da impressionante variedade de exemplos que podemos achar como parte da produção de gravuras makura-e, e da própria heterogeneidade da manifestação.

Aqui, finalmente, voltamos a um aspecto medular de nosso ponto de partida nesta aproximação ao shunga, o desejo e a representação: a forma com que as diferentes comunidades culturais de vários países que interatuaram com estes objetos e imagens ao longo de quase três séculos os interpretaram, utilizaram, e remodelaram, e, portanto a impossibilidade de "ver" ou "ler" de modos iguais ou monolíticos a estas produções. Com bastante recorrência observamos que se tenta mostrar o shunga de um ou outro modo; mais ainda, que se supõe que tal manifestação seja completamente absoluta, inalterável e perpétua, mostrando-nos "isto" é ou era, o shunga, ou "este outro" não é ou não era, o shunga, e negligenciando que, independentemente de sua materialidade, essas imagens e objetos chamados shunga e makura-e foram e são construídos socialmente, e que suas biografias e devires vão além das práticas passadas e de nossas considerações presentes. 


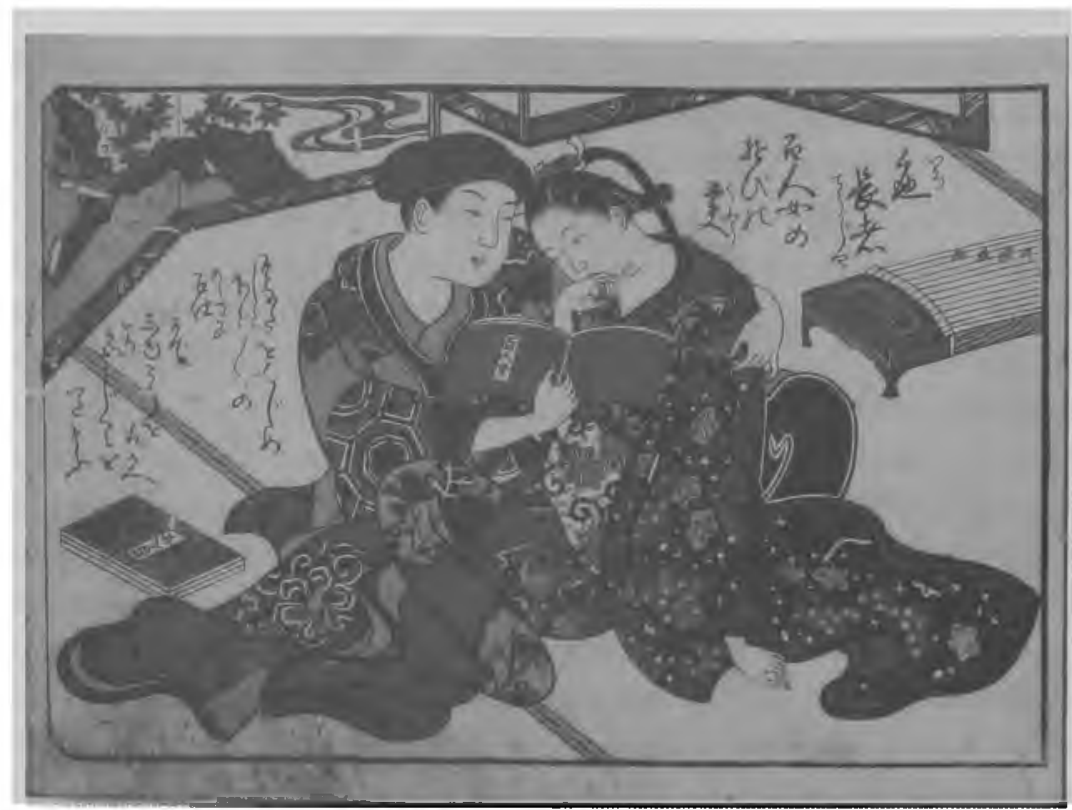

Figura 1. Livro ilustrado. Nishikawa Sukenobu 西川祐信, Hime kagami 比女鑑 (Mulheres Jovens). Aprox. 1752 (Coleção Japan Ukiyoe Museum).

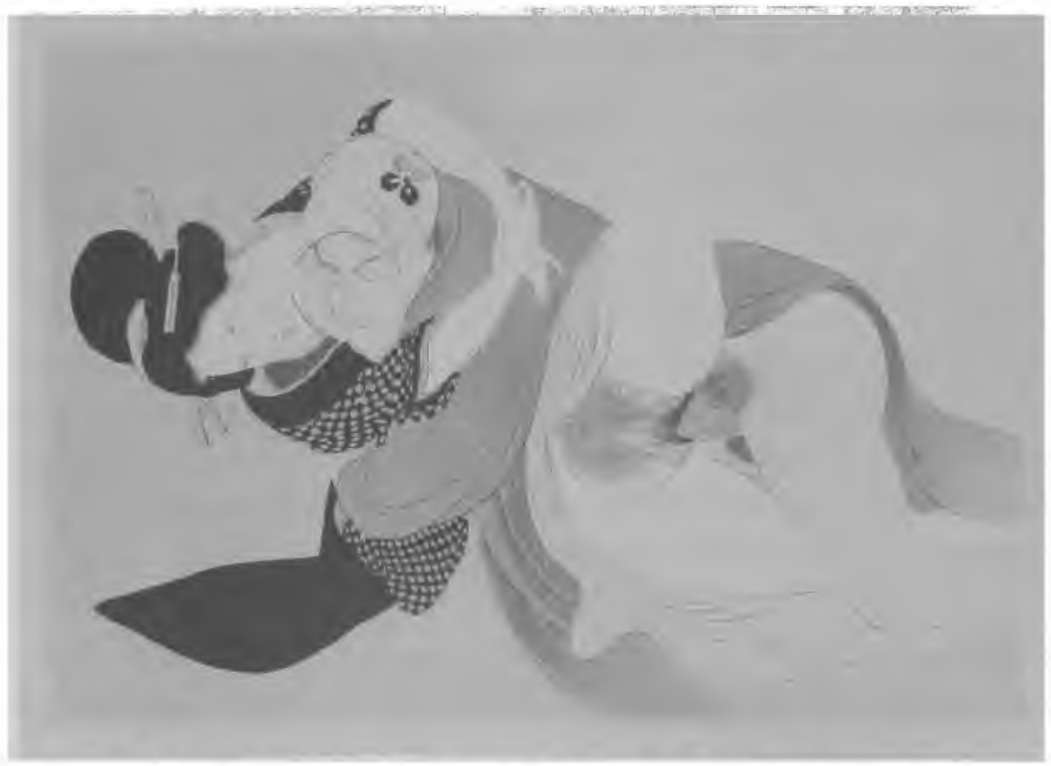

Figura 2.Álbum ilustrado. Tomioka Eisen 富岡永洗, Yakumo no chigiri 八雲の契 (Juras das Oito Nuvens). Princípios do séc. XX. 


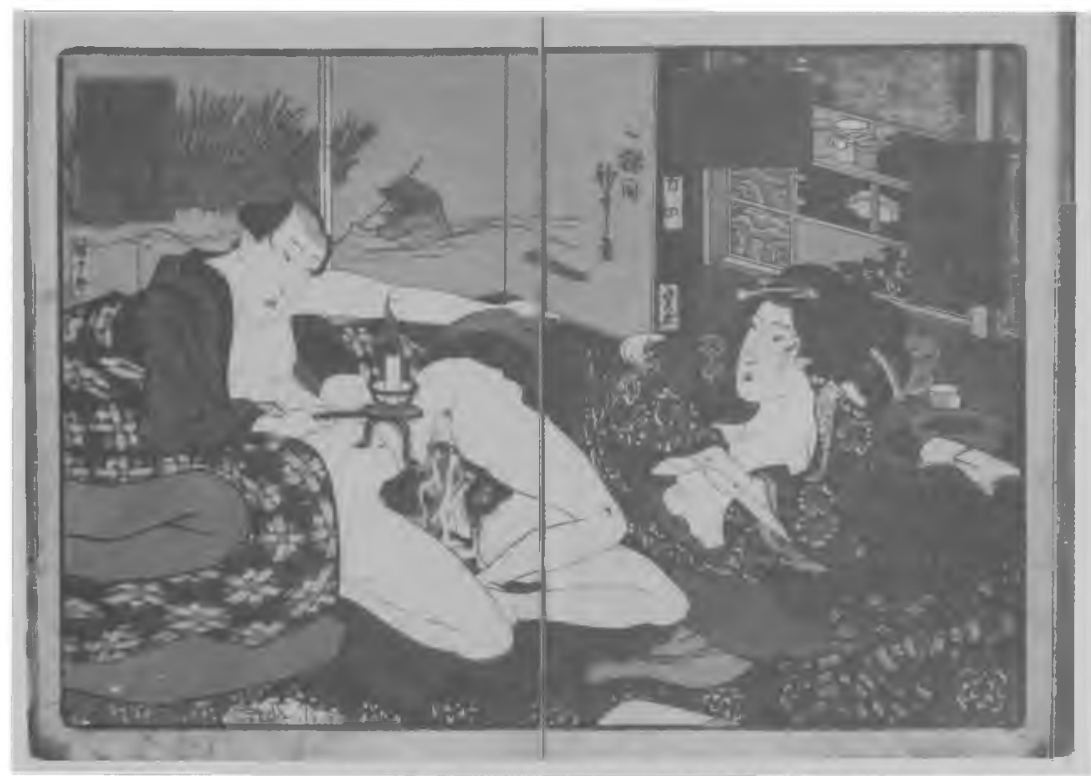

Figura 3. Livro ilustrado. Utagawa Kuniyoshi 歌川國芳, Chinpen shinkeibai 枕辺樑閏梅 (Ameixeiras do Leito Junto ao Travesseiro). 1838 (Coleção Hayashi, Ritsumeikan).

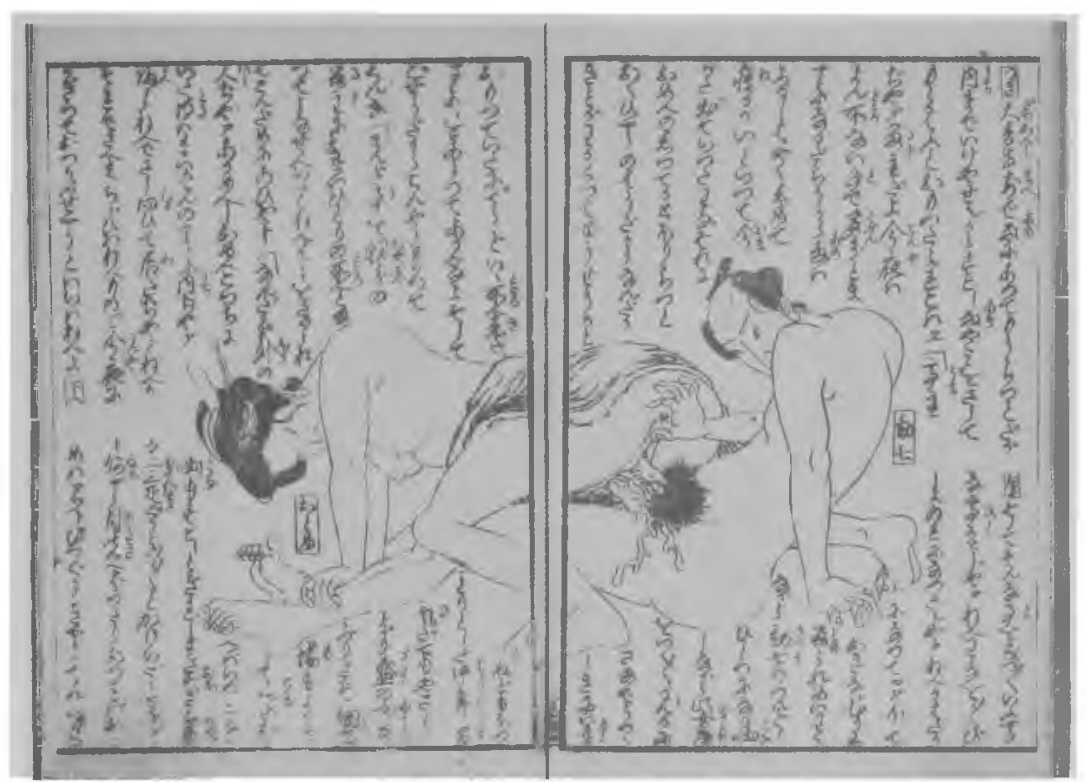

Figura 4. Livro ilustrado. Ryūsuitei Tanekiyo 柳水亭種清, Tsūzoku kanso gundan 通通堪庇軍談 (Histórias Vulgares das Lutas pela Rude Resistência). Aprox. 1818-1850. 


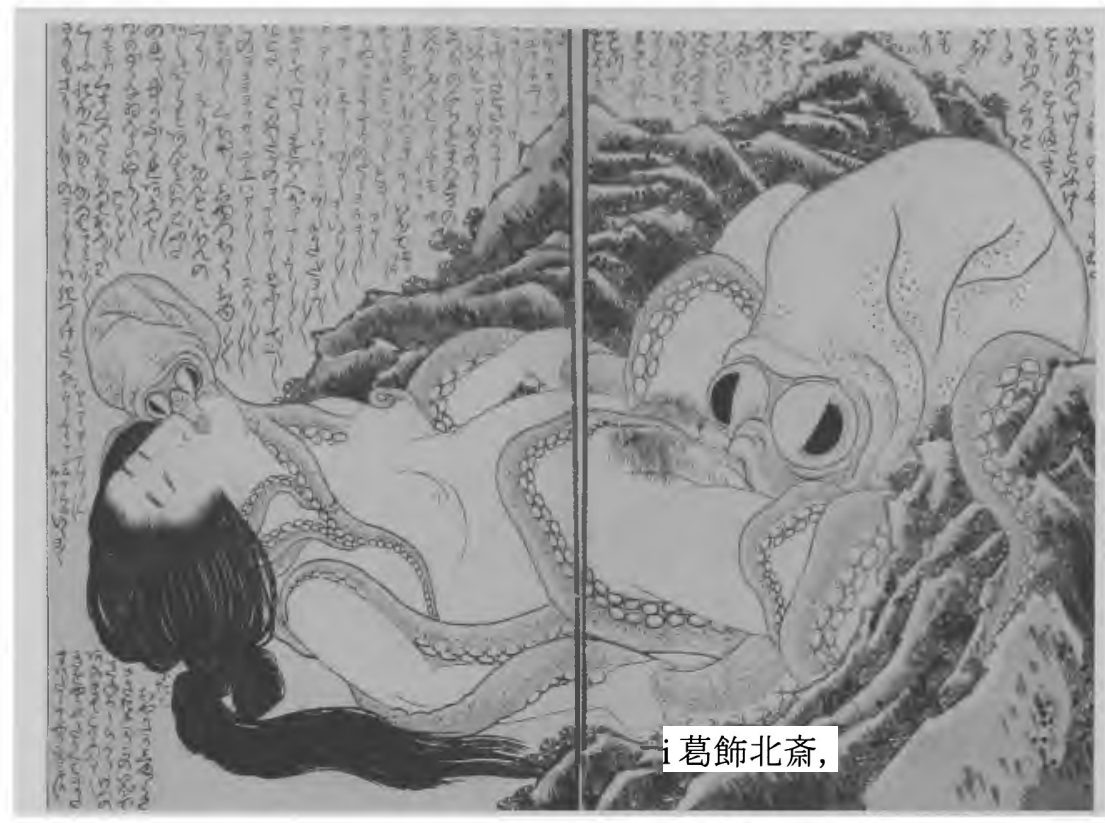

Figura 5. Livro ilustrado. Katsushika Hokusai 葛飾北斎, Kinoe no komatsu 喜能会之故真通 (O Veterano Verdadeiro e Especialista ao Encontro do Deleite Virtuoso). 1814.

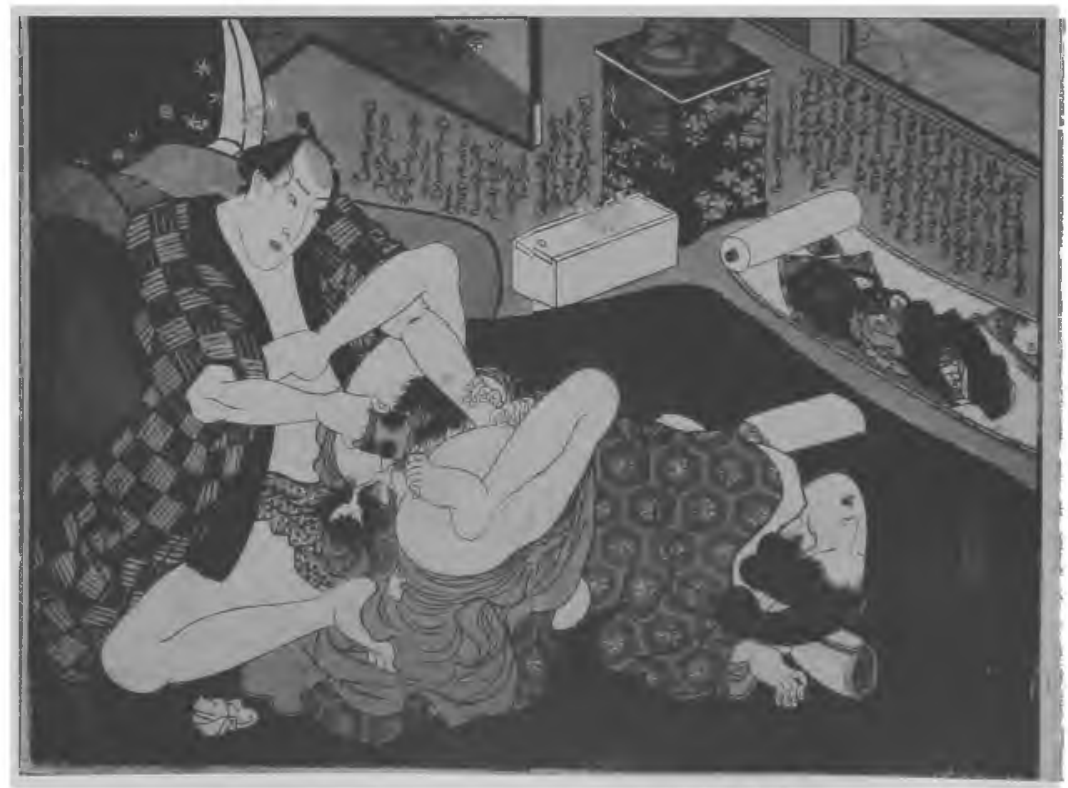

Figura 6. Livro ilustrado. Utagawa Kunimaro 歌川國麿, Shunshoku tama$z o r o i$ 春色多満揃 (Coleção de Muitos Tesouros Eróticos). Aprox. 1850-1867. 


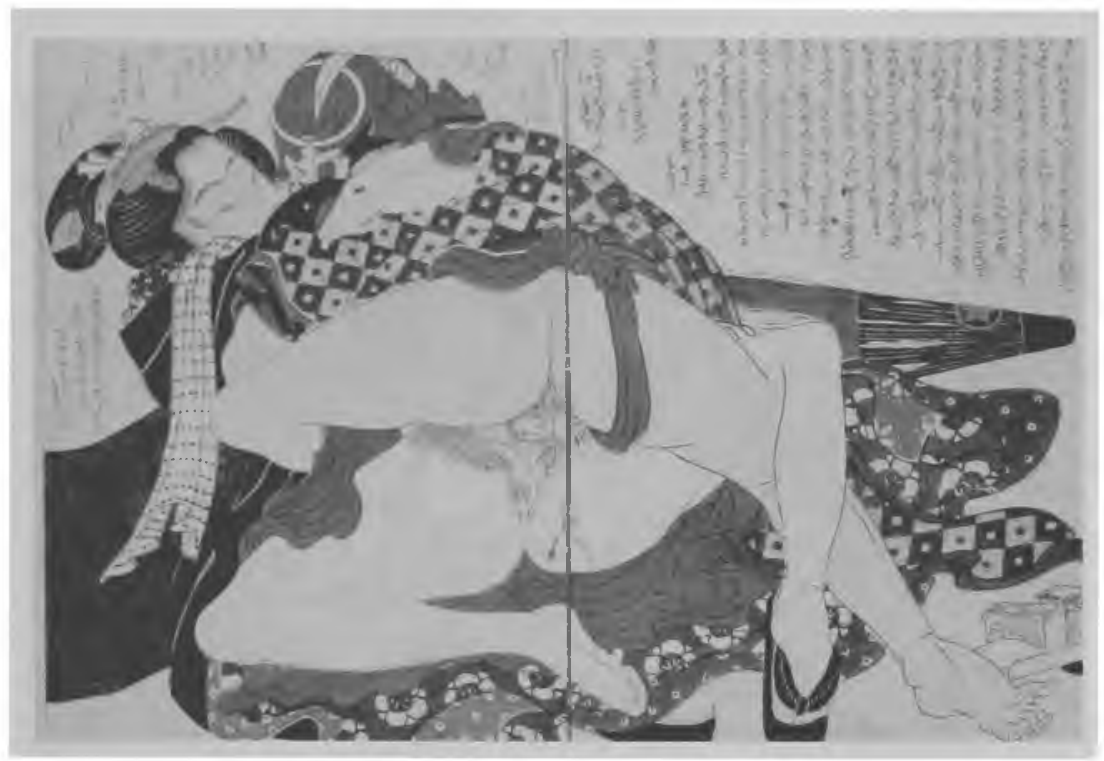

Figura 7. Exemplo de fragmentação anatômica. Livro ilustrado. Keisai Eisen 溪斎英泉, Ehon midare-gami 絵本美多礼嘉見 (Livro Ilustrado das Muitas e Belas Maneiras de Desarrumar-se). 1815.

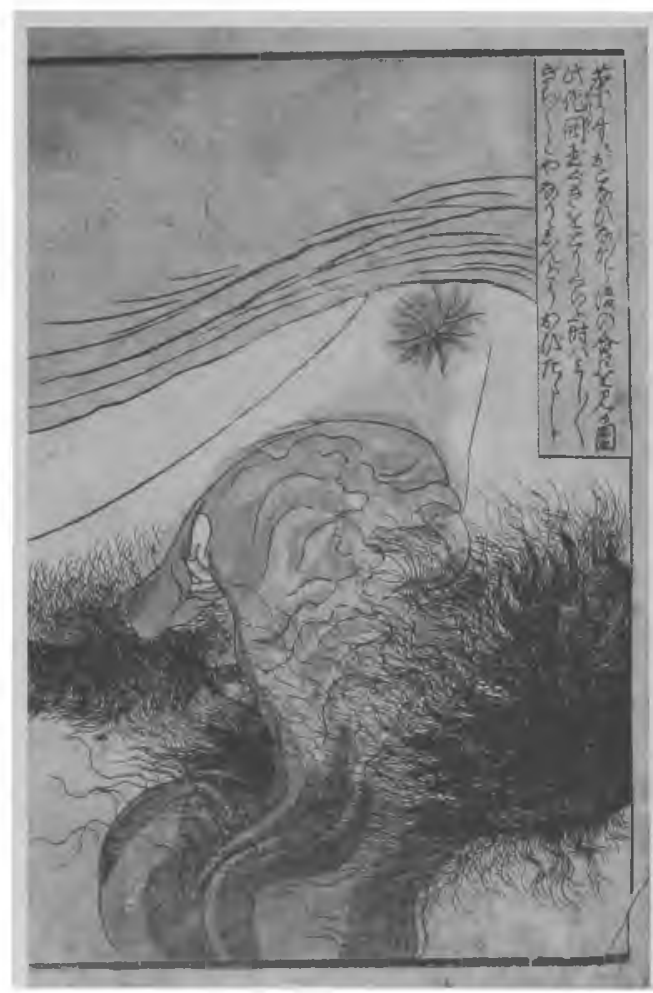

Figura 8. Exemplo de visibilidade boa. Livro ilustrado. Utagawa Kunisada 歌川國貞, Kaidan yoru no tono 開談夜之殿 (Histórias Vaginais Fantásticas do Visitante Noturno). 1826. 


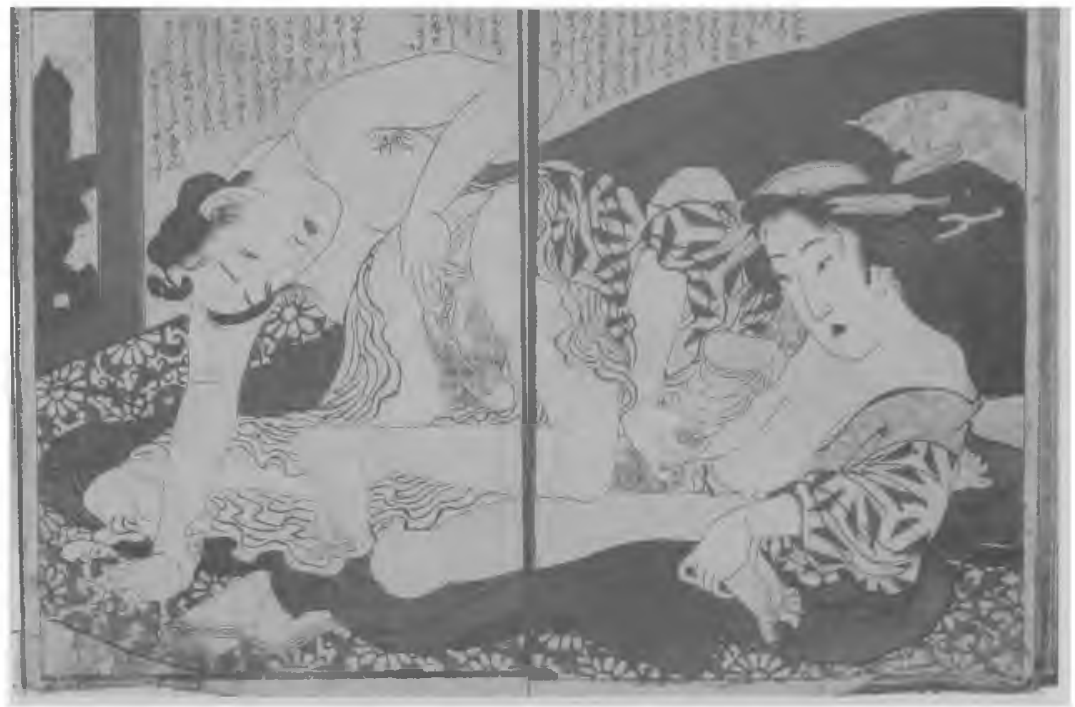

Figura 9. Exemplo de desarticulação do corpo. Livro ilustrado. Keisai Eisen 溪斎英泉, Ehon bime kurabe 艶本美女競 (Competições Eróticas de Mulheres Belas). 1822.

渓斎英泉,

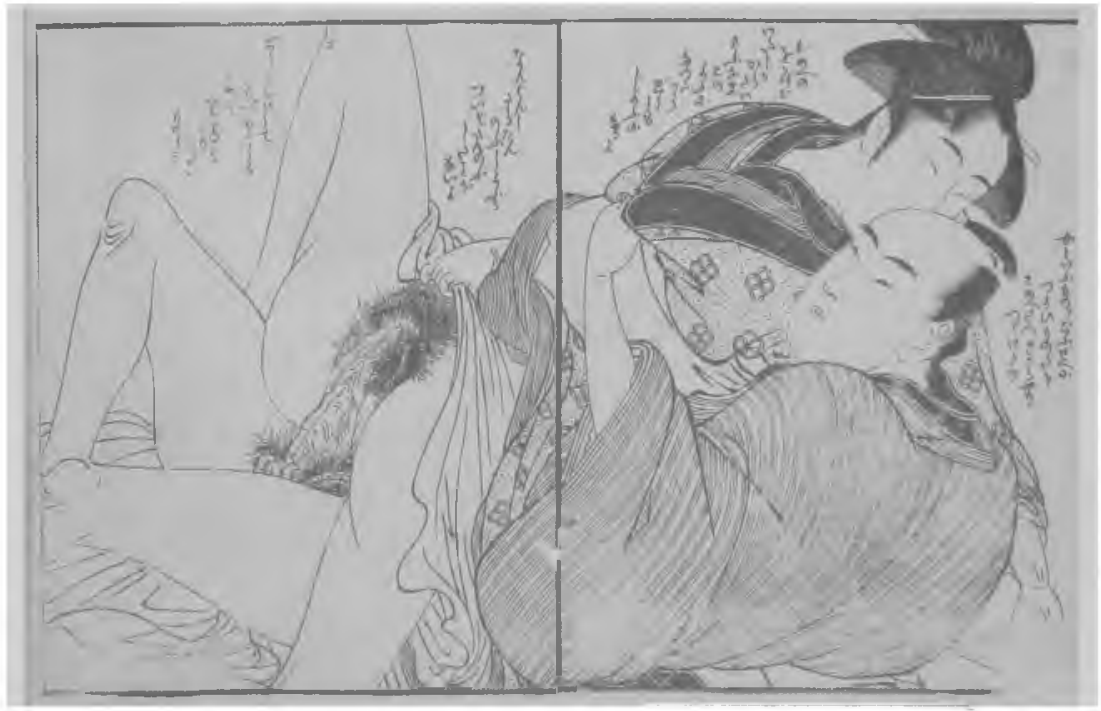

Figura 10. Exemplo de dimensão exagerada dos genitais. Livro ilustrado. Kitagawa Utamaro 喜多川歌麿, Ehon kiku no tsuyu 唈本幾久の露 (Livro Ilustrado do Orvalho Eterno do Gozo). 1786. 
Bibliografia:

APPADURAI, Arjun, ed. The social life of things: Commodities in cultural perspective. Nova Iorque: Cambridge University Press, 1986.

BERMINGHAM, Ann \& John Brewer, eds. The consumption of culture, 1600-1800. Image, object, text. Nova Iorque: Routledge, 1997.

BREWER, John \& Roy Porter, eds. Consumption and the world of goods. Londres: Routledge, 1993.

BRYSON, Norman, Michael Ann Holly \& Keith Moxey, eds. Visual culture. Images and interpretations. Hanover: Wesleyan University Press, 1994.

BUYŌ Inshi 武陽隠士. Seji kenbun-roku 世事見聞録 (1816). Tóquio: Iwanami Bunko, 2002. CHARTIER, Roger. El mundo como representación. Estudios sobre historia cultural. Barcelona: Gedisa, 1995.

COWIE, Elizabeth. "Pornography and fantasy. Psychoanalytic perspectives". In: SEGAL, Lynne (ed.). Sex exposed. Sexuality and the pornography debate. Londres: Virago Press, 1992, pp. $132-152$.

FREEDBERG, David. The power of images: Studies in the history and theory of response. Chicago: The University of Chicago Press, 1989.

GUBERN, Roman. La imagen pornográfica y otras perversiones ópticas. Barcelona: Akal, 2004. JONES, Sumie (ed.). Imaging/Reading eros. Proceeding for the conference: Sexuality and Edo culture, 1750-1850. Bloomington: Indiana University, 1996.

KAWAHARA, Mankichi 河原萬吉. Waidan kikō 猥談奇考. Tóquio: Chōbunkaku, 1928. KITAGAWA, Morisada 喜田川守貞. Kinsei fuzoku-shi 近世風俗志 (1863). Vol. II. Tóquio: Iwanami Bunko, 2003.

MITCHELL, W. J. T. Iconology. Image, text, ideology. Chicago: The University of Chicago Press, 1986.

"What do pictures 'really' want?" In: October. Vol. LXXVII. Cambridge: MIT Press, 1996, pp: 71-82.

SCREECH, Timon. Sex and the floating world. Erotic images in Japan 1700-1820. Cambridge: University of Hawaii Press, 1999.

SHIRAKURA, Yoshihiko 白倉敬彦 (ed.). Ukiyo-e shunga wo yomu 浮世絵春画を読む. 2 Vols. Tóquio: Chūō Koron-sha, 2000.

TAKEDA, Izumo 竹田出雲; MIYOSHI, Shōraku 三好松洛; NAMIKI, Senryū 並木千柳. Kanadehon Chūshingura 仮名手本忠臣蔵 (1748). Charlottesville: University of Virginia Electronic Text Center, 1999. Disponível em World Wide Web em http://etext.lib.virginia.edu/ japanese/chushingura/TakKana.html (15 de Abril de 2006).

UENO, Chizuko 上野千鶴子. "Shisen no sei = seijigaku" 視線の性=政治学. In: SHIRAFUJ, Kayako 白藤花夜子 (ed.). New feminism review ニュー フェミニズム レビュ — Vol. III, Porunoguraf $\tilde{1}$, yureru shisen no seiji-gaku ポルノグラフィー、摇れる視線の 政治学. Tóquio: Gakuyō Shobō, 1992, pp: 92-100. 